Meta

Journal des traducteurs

Translators' Journal

\title{
Hard Work Will Bear Beautiful Fruit. A Comparison of Two Think-Aloud Protocol Studies
}

\section{Riitta Jääskeläinen}

Volume 41, numéro 1, mars 1996

Le(s) processus de traduction / Translation Process(es)

URI : https://id.erudit.org/iderudit/003235ar

DOI : https://doi.org/10.7202/003235ar

Aller au sommaire du numéro

Éditeur(s)

Les Presses de l'Université de Montréal

ISSN

0026-0452 (imprimé)

1492-1421 (numérique)

Découvrir la revue

Citer cet article

Jääskeläinen, R. (1996). Hard Work Will Bear Beautiful Fruit. A Comparison of Two Think-Aloud Protocol Studies. Meta, 41(1), 60-74.

https://doi.org/10.7202/003235ar
Résumé de l'article

Cet article compare les résultats de deux études dont la méthodologie commande aux sujets de traduire tout en exprimant leurs pensées à voix haute. Le but de cette comparaison est de démontrer que 1) en traduction, l'expérience ne rend pas nécessairement la pratique plus facile et 2) que les traducteurs professionnels ne réussissent pas forcément de meilleures traductions que les non-professionnels. La raison pour laquelle l'auteur met l'accent sur des observations aussi peu rassurantes est qu'elles illustrent bien certaines hypothèses sur le rôle des facteurs affectifs en traduction, ce qui se révèle important dans l'enseignement de la traduction. 


\title{
HARD WORK WILL BEAR BEAUTIFUL FRUIT. A COMPARISON OF TWO THINK-ALOUD PROTOCOL STUDIES 1
}

\author{
RIITA JÄÄSKELÄINEN \\ University of Joensuu, Joensu, Finland
}

\begin{abstract}
Résumé
Cet article compare les résultats de deux études dont la méthodologie commande aux sujets de traduire tout en exprimant leurs pensées à voix haute. Le but de cette comparaison est de démontrer que 1) en traduction, l'expérience ne rend pas nécessairement la pratique plus facile et 2) que les traducteurs professionnels ne réussissent pas forcément de meilleures traductions que les non-professionnels. La raison pour laquelle l'auteur met l'accent sur des observations aussi peu rassurantes est qu' elles illustrent bien certaines hypothèses sur le rôle des facteurs affectifs en traduction, ce qui se révèle important dans l'enseignement de la traduction.
\end{abstract}

\begin{abstract}
In this article some of the results of two think-aloud protocol studies (Gerloff 1988 and Jääskeläinen 1990) are compared. The purpose of the comparison is to illustrate two findings: (1) that translation does not always get easier as professional experience increases, and (2) that professional translators do not always succeed better than non-professionals. The emphasis is on these somewhat disturbing observations because they are particularly suitable for illustrating tentative hypotheses about the role of affective factors in translation. These, in turn, have important implications for teaching translation.
\end{abstract}

\section{INTRODUCTION}

Empirical research on translation processes has reflected a relatively wide spectrum of research interests. In some cases, apart from being generally aimed at illuminating the contents of the "black box," the think-aloud protocol studies have shared little else than the methods of data collection. Thus, to mention but a few of the differences, we have studies in which verbal reports hav: been collected from foreign language learners (e.g. Krings 1986; Lörscher 1991), from translation students (e.g. Jääskeläinen 1987, 1989a, 1989b; Nagy 1989; Tirkkonen-Condit 1989), from combinations of students and professional translators (e.g. Königs 1987; Krings 1988), or from professional translators (e.g. Laukkanen 1993; Séguinot 1989a). Similarly, the languages involved have varied as well, depending on where the research has been carried out, including German and French (Krings 1986), English and French (Gerloff 1988; Séguinot 1989), German and English (Lörscher 1991), German and Spanish (Königs 1987), Finnish and English (Jääskeläinen 1990; Laukkanen 1993; Pöntinen and Romanov 1989; Tirkkonen-Condit 1989, 1992), and Finnish and German (Nagy 1989). The kinds of tasks used in the experiments have ranged from oral (Lörscher 1991) to written translation, and from monologic thinking aloud to dialogic thinking aloud (e.g. House 1988; Kußmaul 1991). More importantly, process investigators have approached translation from slightly different angles, thus focussing on analysing different aspects of the process, such as problem-solving strategies (Krings 1986; Lörscher 1991), cognitive planning (Hölscher and Möhle .1987), 
decision criteria (Tirkkonen-Condit 1989), or the focus of conscious attention (Jääskeläinen 1990). Consequently, the methods used in the analysis of the data have also differed considerably.

These differences have very natural causes. The first process-oriented research projects were started in isolation, independently of each other; therefore, the studies reflect very different backgrounds (see Krings 1986). In the absence of previous research, methods of analysis have been developed to describe a particular body of data. Applying the methods of analysis to other kinds of data has resulted in modifications or the introduction of new methods of analysis.

The diversity of approaches can be regarded as an advantage: different studies shed light on different aspects of different kinds of translation processes thus increasing our understanding of the mechanisms underlying translation. Yet the multiplicity of interests is not totally unproblematic. For example, the differences in the kinds of data collected, the kinds of analyses carried out, and particularly the overall goals of research have made it more difficult to test the methods employed in previous studies (see e.g. Jääskeläinen 1993). Although the problem is to some extent understandable in a field that is still in its infancy, not enough attention has been paid to testing and refining the methodology.

Due to the differences listed above, it has been somewhat difficult to compare the results in order to be able to draw more generalisable conclusions. Due to the painstaking methods of data collection and analysis involved in process-oriented research, the number of subjects has remained relatively small. As a result, investigators have been (or should have been) extremely cautious in generalising on the basis of the results. ${ }^{2}$ Particularly in the early stages of process-oriented research, it is very important to be able to back up one's conclusions (or discard or modify them, as the case may be) with the results of other studies. We are still looking for the relevant questions to be asked in protocol studies, as "no significant conclusions can be drawn from an experiment unless all the relevant parameters, along with their relationships, have been identified" (Toury 1991: 182). The search for the identification of relevant parameters is, yet another reason for not increasing considerably the sample size in experiments. With masses of data, some relevant parameters might go undetected.

In this article, I will compare some of the results presented in my licentiate thesis (Jääskeläinen 1990) with those presented by Pamela Gerloff (1988) in her doctoral dissertation. Although our studies differ in several respects, I believe that there is sufficient overlap to justify comparison. The purpose of the comparison is to provide a broader base for further hypotheses and also to develop new ideas through the accumulation of knowledge. After introducing the data in both studies and some of the early hypotheses in process-oriented research, some of the results of these two studies will be discussed. Finally, some tentative hypotheses which have a bearing on my doctoral dissertation will be taken up for discussion.

\section{DATA IN GERLOFF AND IN JÄ̈̈SKELÄINEN}

Both in Gerloff (1988) and in Jääskeläinen (1990), the think-aloud data was elicited from twelve subjects who were asked to produce a written translation of a written source text. Incidentally, both texts were articles dealing with health issues; Gerloff's source text was taken from the French magazine L'Express and Jääskeläinen's from the British scientific journal $N e w$ Scientist. The subjects translated from a foreign language into their native language (with the exception of the competent bilinguals in Gerloff's study. See below). Jääskeläinen's subjects translated from English into Finnish and Gerloff's from French into English. In Jääskeläinen's study the task performances were tape-recorded, 
while Gerloff used both audio- and videotaping. In both studies, the experimenter was present during the sessions.

The subjects formed three groups in both studies. (For more detailed accounts, see Gerloff 1988: 28-30; and Jääskeläinen 1990: 71-76.) In Gerloff's study, the subjects were four college students learning French as a second language, four competent bilinguals with little or no experience in translating, and four professional translators. In Jääskeläinen's, the subjects were four translation students (two first-year and two fifthyear students), four professional translators with 10-15 years of experience (three of them were freelance translators at the time, and one was a business correspondent), and four "educated laymen" whose age and level of education roughly corresponded to those of the professional translators and who had a relatively good knowledge of English but no experience in translating. The student data was collected first to be used in my pro gradu thesis (Jääskeläinen 1987). The composition of subjects in the second set of experiments was based on the assumption that the results of Jääskeläinen (1987), regarding novice and more professional-like behaviour, could be tested by selecting genuine novices and genuine professionals as subjects. That is, the aim was to acquire more information about the features of processing in professional vs. non-professional translation.

Due to the underlying didactic purposes, the quality of the produced translations was also assessed. The results were surprising: some of the professional translators did rather poorly in comparison with some of the novices (first-year students and educated laymen alike). As a result, I changed perspective and decided to look at those features which the successful processes had in common. Within the context of my study, successful processes were defined as those resulting in high-quality products as assessed by four lecturers at the Savonlinna School of Translation Studies. In other contexts and for other purposes successful translation has to be defined according to different criteria (see also section 6). The unexpected results of the quality assessment were not the only reason for the change. Preliminary analyses of the data had already indicated that, with this sample of professional translators, hardly any traits of "professional behaviour" could be identified (the laymen's behaviour was clearly more homogenous). That might simply have resulted from unfortunate idiosyncracies. However, as the "success" of the professionals was not homogenous, the change in perspective seemed justified.

As a consequence, in my licentiate thesis, the results are reported in terms of "quality groups" of subjects, i.e. those who produced good, mediocre, or weak translations, instead of the original "occupational groups." The success or failure of individual subjects in the experimental task is obviously not intended as a label for their translation competence in general. (In what follows I will use, somewhat misleadingly, the terms "good/mediocre/weak processes" instead of the more accurate but more clumsy "processes resulting in good/mediocre/weak products.") In Gerloff's study, on the other hand, the results are reported in terms of the original "proficiency groups," i.e. students, competent bilinguals, and professional translators, although the results of quality assessment in her study (see Gerloff 1988: 135-144) also showed that quality did not correlate with linguistic or translational competence the way one might have expected. The results of translation quality assessments will be discussed in more detail in section 4.1.

\section{EARLY HYPOTHESES}

One of the most frequent hypotheses in the first protocol studies postulated that many thought processes would be automatised in professional translators' translation processses (see Börsch 1986; Krings 1986). Consequently, as automatised thought processes are inaccessible for verbalisation (see Ericsson and Simon 1984), it was assumed that 
professional translators would verbalise little, if anything, of their thought processes. In addition, the highly automatised process would be fast and unproblematic. To make an extreme interpretation of the automaticity hypothesis, it could be argued that it was assumed that we need to acquire data from inexperienced translators, such as language learners and translation students, to be able to know what is missing from the professional translators' automatised, hence silent, processes. This hypothesis is supported by Candace Séguinot's study (1989), in which a government translator was videotaped while carrying out a routine translation task. The subject produced relatively few verbalisations and her processing patterns had to be inferred by observing behaviour, such as pauses and hesitations in typing.

However, as more research was carried out, the automaticity hypothesis proved to be too crude. For example, in Sonja Tirkkonen-Condit's study (1989), the more professional subjects made (and verbalised) more decisions than the less experienced subjects. Similarly, in Hans-Peter Krings' study (1988) with a professional translator as a subject, the professional engaged in considerably more processing than the foreign language learners who had translated the same text earlier (Krings 1986). For example, he problematised more source text items and used reference material more often than most of the language learners in the earlier experiments. Similar results were obtained by Gerloff (1988) and Jääskeläinen (1990). It was found that professional translators did not necessarily spend less time and effort on the experimental translation tasks than less professional subjects. Gerloff (1988: 54ff.) called this the "Translation Does Not Get Easier" phenomenon.

The following comparison of Jääskeläinen (1990) and Gerloff (1988) is aimed at demonstrating this phenomenon in two bodies of data. More specifically, the purpose is to illustrate two points: (1) that not all translation processes are carried out more quickly and more easily as professional experience increases, and (2) that the time and effort invested in the process is likely to be reflected in the quality of the product (irrespective of how experienced the translator is). These statements may appear to be exaggerated and yet obvious. In fact, focussing on these points serves an ulterior motive. This perspective provides the relevant background for the discussion of the role of affect in the final sections of this article.

\section{COMPARISON OF THE RESULTS}

\subsection{Translation Quality Assessment}

In both studies the translations produced were evaluated by a group of raters. (More detailed accounts of translation quality assessment can be found in Gerloff (1988: 135144) and in Jääskeläinen (1990: 97-105).) In Gerloff there were three raters, one of whom was the experimenter. In Jääskeläinen the raters were four lecturers at Savonlinna who were not informed as to the translators' professional ability. In addition, the translations were sent to the co-editor of the national newspaper for which the text was supposed to be translated; his comments were very similar to those of the lecturers, except that he was much more broadminded in what he would allow to be published in his column ("if edited a little").

Both quality assessments were general and impressionistic; the raters were asked to give an overall rating with some comments. The assessment criteria differed slightly. In Gerloff the raters were asked to take into account two central factors: "accuracy or faithfulness of meaning to the French text and readability of the final English product" (1988: 135). In Jääskeläinen's study, the raters were asked to pay special attention to how well 
the translations fulfilled the requirements set by the task description; for that purpose, the raters were given copies of the target text. The task description required some editing of the source text. For example, some totally irrelevant information was to be left out. (The task description entailed some rewriting. For the more puristic this makes the task "a rewriting task" instead of a translation task.) Semantic accuracy and linguistic fluency were also used as criteria. Results of the translation quality assessments are presented in Table 1.

\begin{tabular}{|l|l|}
\hline Gerloff & Jääskeläinen \\
\hline BEST & GOOD \\
3 translators & 2 translators \\
1 bilingual & 2 fifth-year students \\
& MEDIOCRE \\
VERY GOOD & 1 translator \\
1 bilingual & 2 first-year students \\
1 student & 1 educated layman \\
& \\
GOOD & WEAK \\
1 translator & 1 translator \\
2 bilinguals & 3 educated laymen \\
1 student & \\
WEAK & \\
2 students & \\
\hline
\end{tabular}

Table 1: Results of the translation quality assessment.

In my opinion, the most striking observation in Table 1 is that official professional status does not seem to be an automatic guarantee of success, at least not in all kinds of translation tasks. Nor is better language proficiency. These results were dramatic enough for me to reformulate my basic research question and look at features of successful processing instead of features of professional processing. (The results of various analyses were also examined for emerging patterns of professional behaviour; see Jääskeläinen (1990: 210).) In Gerloff's study, the professional translators on the whole succeeded better than the competent bilinguals who in turn did better than the student subjects. However, the slightly unexpected results led Gerloff, too, to look at the process features shared by the successful processes (see section 4.2.).

In spite of the fact that the categories of subjects in Gerloff and in Jääskeläinen, i.e. proficiency $v s$. quality groups, are not wholly comparable, I will retain them in the following comparison of some other findings. The other two possibilities - reanalysing data either in terms of quality groups in both studies, or in terms of Gerloff's proficiency groups and my original occupational groups - would not produce more easily comparable categories of subjects.

\subsection{External Behaviour and the Amount of Processing Activities}

In this section three kinds of quantitative analyses will be looked at. Two of these relate to the subjects' external behaviour, i.e. the amount of time spent on the translation 
process (the time was not limited), and the number of times reference material was used. The third aspect is the total amount of processing activities carried out by the subjects. The results will be presented as mean figures for each of the three groups in each study. These statistics should obviously be interpreted with caution as each group of subjects only consists of four people. Furthermore, quantitative analyses can on the whole be somewhat misleading and uninformative. For the present purposes, however, this form of presentation seems most appropriate to illustrate significant similarities which can be seen as manifestations of the "translation does not get easier" phenomenon.

Table 2(a) shows how much time each of the three groups spent on the process (see also Gerloff 1988: 58; Jääskeläinen 1990: 136-137). The length of the source texts was 181 words in Gerloff and 144 words in Jääskeläinen. Table 2(b) shows the total number of times dictionaries and other reference material were consulted by each group of subjects (see also Gerloff 1988: 106-107; Jääskeläinen 1990: 147-162).

\begin{tabular}{|l|l|}
\hline Gerloff (proficiency groups) & Jääskeläinen (quality groups) \\
\hline TRANSLATORS: $43 \mathrm{~min}$. & GOOD: $74 \mathrm{~min}$. \\
BILINGUALS: $58 \mathrm{~min}$. & MEDIOCRE: 65 min. \\
STUDENTS: 33 min. & WEAK: 36 min. \\
\hline
\end{tabular}

Table 2(a): Time spent on the processes (mean).

\begin{tabular}{|l|l|}
\hline Gerloff (proficiency groups) & Jääskeläinen (quality groups) \\
\hline TRANSLATORS: 24 & GOOD: 20 \\
BILINGUALS: 7 & MEDIOCRE: 18 \\
STUDENTS: 14 & WEAK: 10 \\
\hline
\end{tabular}

Table 2(b): Total number of dictionary consultations (mean).

The above figures indicate that professional translators do not always translate faster than non-professionals. On the other hand, speed also seems to have an interesting relationship to translation quality. For example, the professional translator in the 'weak' category in Jääskeläinen spent the least time ( 22 minutes) on the process (of all the subjects). Professional translators also seem to be the most enthusiastic dictionary users in Gerloff's study. Furthermore, Jääskeläinen's results indicate that success seems to be related to the intensity of research activities in the form of dictionary consultations.

Finally, the quantities of the main categories of processing are presented in Table 3 . In Gerloff (1988: 43), the main category of processing is called problem-solving activities, which are described as follows: "The Problem Solving Activity coding includes both strategies and behaviours used in problem solving." The analysis covers both verbalisations and actual behaviours. In Jääskeläinen, the unit of analysis was labelled attention unit, which I have called instances of marked processing. Those are defined as "those instances in the translation process in which the translator's 'unmarked processing' is interrupted by shifting the focus of attention onto particular task-relevant aspects" (1990: 173). Unmarked processing refers mainly to reading the source text aloud or producing a fluent, uninterrupted translation of a source text item or passage. The analysis covers the subjects' verbalisations and includes both problem-solving activities and unproblematic 
decision-making. Although these two categories do not cover exactly the same kinds of processing, we can look at the inter-group differences in the amount of processing activities.

\begin{tabular}{|l|l|}
\hline Gerloff (proficiency groups) & Jääskeläinen (quality groups) \\
\hline TRANSLATORS: 507 & GOOD: 115 \\
BILINGUALS: 402 & MEDIOCRE: 113 \\
STUDENTS: 330 & WEAK: 53 \\
\hline
\end{tabular}

Table 3: Total amount of processing activities (mean).

The figures in Table 3 show rather convincingly that translation does not get easier. Moreover, it seems that the effort invested in the process bears fruit as higher translation quality.

Gerloff (1988) includes the following processing features in her tentative profile of successful translation: the best translators "spent a good deal of time on the translation -, were moderately high to very high volume processors, [and] generated lots of translation solutions." In Jääskeläinen, the features of the more successful (good and mediocre) processes as opposed to the weak processes include the following features: spending more time on the process, consulting dictionaries more often, and carrying out more processing activities. In addition, in the "better" processes more attention was paid to refining the target text by taking into account stylistic appropriateness and the needs of the target audience (the differences in terms of source text analysis will be discussed in section 5). In sum it seems that in both experiments those subjects who spent considerable time and effort on the experimental tasks were the ones who produced the best translations, irrespective of their relative translation competence or level of language proficiency.

However, we should not jump to any hasty conclusions. As Gerloff points out (1988: 161), "it is important to keep in mind that this study did not find a complete and direct relationship between specific translation processes and quality of the translation product." Neither did Jääskeläinen's study. Although "pronounced trends" are easily identifiable in the data, it is equally obvious that "some individuals do not fit the patter" (Gerloff 1988: 161). Furthermore, as regards the professional translators' unexpected behaviour, it seems very important to look for potential explanations for such discrepancies partly because of the need to find sources of variability for identifying the relevant parameters. One such attempt (Jääskeläinen, in print) indicates that there may be a relevant relationship between the subjects' role behaviour reflecting their self-image and the process-product associations. Other potentially relevant phenomena will be discussed in sections 5 and 6.

\subsection{Discussion}

The findings illustrated above seem to provide convincing evidence that translation does not necessarily get easier with increasing professional experience. As was mentioned in section 3, similar results were obtained by Krings (1988) and Tirkkonen-Condit (1989). Translation quality appears to be closely linked with how much time and effort translators are willing to invest in the process. These findings provide an opportunity to refine some of the earlier hypotheses about automaticity in translation. The refinements relate to (1) the nature of the translation task, and (2) the professional ability of the translator. 
The translation tasks used in Gerloff (1988), Jääskeläinen (1990), Krings (1988), and Tirkkonen-Condit (1989) represented a non-routine task, i.e. a novel, untypical task, for the professional translators. In contrast, the task in Séguinot (1989) was a routine task. Now, it seems highly likely that professional translators will behave differently depending on whether they are carrying out a routine task or a non-routine task. Furthermore, applying a routine approach to a non-routine task, or vice versa, may have undesirable consequences.

On this basis, we could form the following hypotheses about "developmental stages" in translation (see Jääskeläinen 1990: 55-56). Genuine novices in translation problematise relatively little. As a result, they translate quickly and effortlessly (and perhaps wrongly, depending on the difficulty of the task), i.e. novices are blissfully unaware of their ignorance. In contrast, semi-professional translators, such as translation students, have become aware of their ignorance and grown sensitive to potential problems. As a result, their processing can be very arduous and time-consuming. Finally, in relation to professional translators, two alternatives seem plausible: When professional translators perform routine tasks, their processing is likely to be highly automatised hence the process is relatively fast and effortless and little is verbalised. When professional translators encounter a non-routine task, they need to resort to conscious, non-automatised processing which consumes lots of time and energy.

Another important observation, which will not be discussed in full detail in this context, is that professional and non-professional processes differ qualitatively. That is, while some kinds of processing gradually become automatised, other kinds of processing will take up the released processing capacity in working memory (see Jääskeläinen and Tirkkonen-Condit 1991: 105; Gerloff 1988: 54). Thus, there will be more processing capacity to be used for, say, higher-level text production strategies than in the processes used by novices.

At this point a frustrated reader might want to ask: What is the use of being a professional translator, then, if there are no green pastures in sight, no laurels to rest on? The picture is not that grim, however. First, routine task performances are likely to grow faster and easier. In Johanna Laukkanen's recent pro gradu thesis (1993), the purpose was to examine the routine $v s$. non-routine distinction by asking one professional translator to carry out both kinds of tasks. The subject spent 111 minutes translating the routine text which was 168 words in length. The non-routine text, 65 words long, was translated in 97 minutes. (The translation tasks were from Finnish into English, and thus these figures refer to the number of words in the Finnish source texts.) A very unorthodox, but highly illustrative computation of Laukkanen's data shows that in the routine task the professional translator translated 1.5 words per minute, whereas in the non-routine task her "translating speed" was 0.7 words per minute. Although we obviously do not translate words per minute, this can be seen as indicative of faster processing in the routine task.

Second, professional translators have the upper hand in that they know when to employ the easier routine approach or the more demanding non-routine approach-and they also have the opportunity to do so. For a novice there simply is no easy way out. (See also Chesterman (in print) on alternating between conscious "actions" and unconscious "operations" in translation.) Third, although non-routine tasks may demand considerable time and effort to be completed successfully, professional translators have been found to become more efficient in their processing. That is, professional translators carry out more processing in less time than the less experienced translators. In TirkkonenCondit (1989), the more advanced translation students were more efficient processors in that they made more decisions per unit of time than the less advanced students. Similarly, in Gerloff (1988: 147), the professional translators exhibited more problem-solving 
behaviour per unit of time than either the students or the competent bilinguals; hence they could be regarded as more efficient processors. In sum, there are benefits to be gained from professionality in translation, although the nature of these benefits may not be exactly the same as was assumed in the less informed hypotheses.

\section{WHAT DIFFERENTIATES "GOOD" FROM "MEDIOCRE" PROCESSES?}

The tables in section 4 indicate that, in Jääskeläinen's study (1990), the good and mediocre processes are very similar to each other and distinctly different from the weak processes. The same applies to other aspects of analysis as well. In fact, the only feature where the good $v s$. mediocre processes seem to differ is the distribution of instances of marked processing in the analysis of the source text (ST processing). Instances of marked processing in ST processing are divided into two subcategories labelled (1) linguistic analysis and (2) text comprehension (see Jääskeläinen 1990: 206-211). For the present purposes, their difference can be described as (1) reliance on linguistic knowledge, and (2) application of world knowledge. When subjects are translating into their native language, the distinction between these two categories could also be roughly characterised as looking for answers to questions "What is X in Finnish?" vs. "What is X?" (This charaterisation does not necessarily apply to all kinds of tasks, such as translating from one's native language into a foreign language; see Laukkanen 1993.)

The following excerpts from the subjects' protocols illustrate the difference. The first two excerpts show instances of linguistic analysis. Example 1 shows a professional translator looking up unknown lexical items in a bilingual dictionary; in Example 2, another professional translator wishes to find out how the medical term "triglyceride" is spelt in Finnish. The excerpts have been translated into English as literally as possible. The capitalised portions were in English in the original verbalisations.

Example 1. Professional translator ('good') looking up unknown lexical items in a bilingual dictionary.

that DICKY HEART is (.) this word DICKY is unfamiliar to me [consults a bilingual dictionary] (12.0) uhm so it's the same as IF YOU HAVE A BAD HEART (7.0) and at the end of the second paragraph is the word LIPIDS [consults a bilingual dictionary which offers no help] (25.0) it's not in here (sigh) (8.0) (sigh) (4.0) BUT ADDING GARLIC OIL TO THE SAME HIGH-FAT DIET PREVENTED THE RISE OF THE FATTY CONSTITUENTS (26.0) well some other source is needed for figuring out that word (1.0) it could be found in that for instance (8.0) [taps on a monolingual dictionary of English]

Example 2. Professional translator ('weak') on the medical term "triglyceride."

it's presumably triglyceride in Finnish too but well its correct spelling is what (1.0) what cannot be found at least (4.0) not in these (3.0) [referring to the available dictionaries]

Examples 3 and 4 illustrate those verbalisations which have been categorised as instances of text comprehension. In example 3, a professional translator (the same as in Example 1) comments on the modifier "safely" in the ST sentence "However, the search for a miracle drug that could safely mop all the excess fats has been somewhat difficult... but could garlic come to the rescue?" Example 4 shows yet another professional translator's reactions to the medical term "triglyceride" (see also Example 2).

Example 3. Professional translator ('good') on the adverb "safely."

finding such a miracle drug that (3.0) could (5.0) er that would be able (5.0) (sigh) SAFELY safely or without danger (3.0) safely (1.0) here it'd be of course interesting to know what (1.0) what does this mean this SAFELY what dangers could be involved (4.0) 
Example 4. Professional translator ('good') on the medical term "triglyceride."

triglyceride (.) what would that be in Finnish (4.0) triglyceride but what's it then (2.0) what is it as a substance because I don't know these chemical (6.0) well it doesn't really matter that much in a translation whether you know what they include but out of interest always if something should stick (1.0) stick to mind cos' don't know about these (1.0)

In relation to the inter-group differences in $S T$ processing the mediocre and weak processes resemble each other. The share of linguistic analysis in the mediocre and weak processes is $65 \%$ and $73 \%$ respectively (the remaining $35 \%$ and $27 \%$ of ST processing belonging to the text comprehension category). In contrast, in the good processes the ratio is $38 \%$ vs. $62 \%$; that is, in the good processes most of the attention is directed at text comprehension, at relating the text to the extra-textual world. The less successful processes seem to remain more exclusively at the linguistic surface level.

However, the relationship between the kinds of processing illustrated in Examples 3 and 4 and the quality of the products is not as simple as it sounds at first. One might expect that focussing attention on the linguistic surface features at the expense of paying attention to the contents will lower translation quality by introducing factual mistakes into the text. However, in the present experimental task this did not happen. None of the translations contained any significant factual misinterpretations. For example, the result of either checking the spelling of "triglyceride" (Example 2) or doing a lengthy analysis about its qualities (Example 4) is the same. The Finnish medical term is triglyseridi.

In this respect, then, a tentative hypothesis assumes that the key phrases in the excerpts presented above are "it would be interesting to know," and "out of interest." That is, it seems to be the attitude conveyed in these verbalisations that differentiates between the good and the mediocre results. The puzzling and extremely complex question of how attitude is reflected in the translations, except as vague "quality," will have to be addressed later. Here I would like to draw attention to other observations that seem to provide support for the impression that the translator's attitude during the process contributes to the quality of the product. More generally, it seems that affective factors, be they personal involvement, commitment, motivation, or attitude, play a significant role in translation as well as in other forms of human behaviour.

In Gerloff's study, the competent bilingual group showed the largest intra-group variation in terms of quality. By way of offering a potential explanation for this variation, Gerloff (1988: 153-154) points out:

Bilinguals may, for example, view some tasks as "important" and others as "insignificant", whereas a translator or a student may be more likely to give all school- or work-like tasks roughly equal weight. In this study, Mark, the bilingual who spent only 12 minutes on his translation, considered the article to be translated "unimportant", because of its content. If it had been, for example, a "biblical" translation that he had been asked to do, he would have spent more time and effort on it.

To my mind, Gerloff's observation also indicates that in comparison with the other bilinguals, Mark may have been considerably less motivated, or less involved, than, for instance, Tina who produced the best translation (of all the subjects) and spent the most time (111 minutes) on it.

In Laukkanen's study (1993), there appears to be a clearly identifiable affective difference between the professional translator's routine and non-routine processes which is linked to the quality of the target texts. Confidence in the routine task resulted in a critical attitude which in turn resulted in better quality. Insecurity in the non-routine task resulted in too heavy a reliance on the source text which lowered the quality of the target text. Furthermore, Paul Kußmaul's (1991) dialogue protocols indicate that for creative insights to occur an atmosphere of positive encouragement is necessary. 
However, high involvement appears to be a double-edged sword; in the wrong hands the results may be disturbing. Tirkkonen-Condit (1992) compares the processes carried out by a professional translator with those carried out by a non-professional translator. The source text dealt with the non-professional subject's field of expertise, of which she naturally had very strong opinions and preconceptions. As a result, she was at times so taken up with her emotional reactions to the contents of the source text that she ended up distorting what it said. In other words, a delicate balance between personal involvement and intellectual detachment seems to be necessary in some translating situations.

\section{CONCLUSION}

This article draws together some of the results of two different think-aloud protocol studies in order to make more feasible generalisations about particular features of translation processes. The emphasis has been on looking at those features which show that (1) translation may not get easier; (2) professionals may not always succeed; and (3) affect may play a central role in success. Admittedly, the samples on which these generalisations are based are still very small, and with such small samples one needs to be very cautious, particularly in terms of quantitative analyses. However, the findings discussed here show that these phenomena merit further investigation. The aspect that most attracts my attention is the role of affective factors in translation, particularly in relation to translation quality. On the one hand, the evidence so far seems to indicate that affective factors may be a relevant parameter in accounting for translational behaviour. On the other hand, the prospect that affective factors influence translation quality has significant didactic implications.

The role of affect in translation (as in any kind of cognitive activity, see e.g. Izard, Kagan, and Zajonc 1984) should be investigated more thoroughly and should not be underestimated. Yet the role must not be overestimated either, as it is likely that not all tasks or not all translators require similar levels of motivation in order to be successful. In a slightly different context, in relation to particular motivational factors and productivity, John W. Atkinson (1974: 217) points out:

- no work situation is optimal for everyone, no type of personality is most productive in all situations, no single generalisation about the effects of strength of motivation will apply to all tasks. It means, more specifically, that for every particular occupational role, there is a different kind of most productive personality. And for every personality, the anxiety-prone no less than the positively motivated, there is a particular role which offers an opportunity for relatively greater productivity and relatively greater contribution than others as a solid foundation for the individual's self-esteem.

In other words, different kinds of personality traits are desirable for different kinds of jobs. Similarly, considering the wide variety of occupational choices available for graduates of translator training programmes, such as interpreters, technical editors, TV translators, literary translators, Bible translators, legal translators, business correspondents, or free lance translators in a field of their own choice, to mention but a few, it is obvious that different occupations attract different kinds of personalities.

However, at least in my experiments, the experiment design and the subsequent analyses were clearly biased towards a particular kind of translator. Therefore it does not seem a coincidence that the weakest professional task performance in my study was that of the only business correspondent among the three freelance translators. For one thing, the experimental translation task represented a non-routine task for the professional translators. ${ }^{3}$ In non-routine tasks interest, high motivation, and other similar qualities are likely to be desirable for high quality products. These, in turn, are qualities that may be 
expected to be more salient in, say, freelance translators who, on the one hand, may have more variety of commissions thereby more easily retaining their "mental flexibility" (see Chesterman, in print; Toury 1984). On the other hand, in the case of freelance translators their daily bread may depend more crucially on the quality of their work than in the case of someone on a company payroll, particularly if the company measures successful translation in terms of quantity rather than quality. Such a company policy is precisely what the business correspondent in my study revealed by her comment: "If I spent an hour and a half on translating half a page, I would have been fired ages ago."

The reason for drawing attention to the experimental bias is to stress that the purpose of looking at success of a particular kind in a particular kind of situation is not to introduce yet another form of an "optimal translator" (Toury 1984; see also e.g. Jääskeläinen, in print) into the discussion (hence the question mark in the headline of this article). According to Gideon Toury (1984: 189), the goal of translator training "tends to be one brand or another of an 'optimal translator'." The optimal translator seems to be the invisible "hypothetical construct" (Toury 1984: 187) hiding between the lines of some translation theoretical contributions. The optimal translator, as most mythical creatures, has unlimited resources at his or her disposal (i.e. he or she operates under optimal work conditions) and is therefore, naturally, able to produce optimal, perfect translations. The "model" of the optimal translator who, after doing every kind of sophisticated analysis, invariably produces perfect translations, can be very detrimental to translators' selfesteem.

In addition to being able to produce perfect translations, one brand of the optimal translator may be the professional who spends little time and effort on translation tasks. While under some circumstances this holds true, it does not apply to all situations or all translators. The point is that the various brands of the optimal translator create false expectations in students and professionals alike, which in turn can have harmful consequences. Gerloff (1988: 155-156) formulates the danger as follows:

Although, upon reflection, this observation [that translation does not get easier] "makes perfect sense", there is nonetheless - among teachers and students as well as the general populace - a strong ethos and a deeply ingrained expectation that foreign language tasks such as translation should get easier; and that those engaged in such endeavours should get faster at them. One unfortunate result of such a belief is that the expectation itself may in fact influence people's processing and performance of language tasks in not altogether constructive ways. Comments reveal subjects' expectations about what the process should look like, as well as underlying beliefs or suspicions about their own perceived inability to live up to those expectations. They judged their process against standards which this research suggests are inaccurate representations of the true nature of the translation process.

If professional translators, let alone translation students, constantly work under the impression that they fail because they do not live up to the false expectations embodied in some brand of the optimal translator, their confidence and self-esteem are seriously undermined. Similarly, Hans G. Hönig $(1988 ; 1992)$ has drawn attention to the evaporating self-esteem of translation students, its causes and consequences. Since confidence and positive attitudes seem to go together with high quality at least in some translating situations, it would be of utmost importance to enhance translators' self-esteem instead of making it disappear.

The optimal translator in translation studies has an interesting parallel in psychology. According to Darlene Howard (1983: 424-425), decision theories, particularly in economy, have been largely built on the notion that human beings are optimisers or maximers. That is, in making decisions people weigh all the alternative actions and outcomes and eventually choose the best possible alternative, i.e. the one with the optimal 
cost-effect ratio. However, Herbert A. Simon $(1956,1979)$ observed that instead of being optimisers, human beings are satisficers; i.e. in making decisions "people accept a choice that is good enough rather than continuing to search for one that is the best possible" (Howard 1983: 424). The basis of this characteristic is in the nature of the human information processing system with its limited capacity work-space. Therefore, "we are well designed to be satisficers, but poorly designed to be maximisers" (Howard 1983: 425).

The myth of the optimal translator seems to reflect the same kind of thinking as the view of human beings as optimisers, which also seems to explain the huge gap between "the needs of translation pedagogy and that which is offered by a theory" (Toury 1984: 188). Or, for that matter, the huge gap between the theory and the practice of translation that tends to frustrate translation students (Jääskeläinen 1990: 43ff.). Consider the prescriptive branch of translation theory which aims at giving instructions about how to behave in order to produce perfect translations. While we obviously need some kinds of measures (i.e. norms) to be able to assess translation quality, to teach translation, and simply to be able to translate in the first place (see Chesterman, forthcoming), perfect translation as the goal places too high demands on translators. It seems to me that what we need to do is to bring down the norms a little; instead of giving instructions about how to make perfect translations, we should focus on what is humanly possible. This is where I think process-oriented research on translation can offer help by looking at the not-so-perfect processes which nevertheless yield products that are certainly good enough.

In conclusion, the ideas discussed in this article are intended primarily as food for thought, as hypotheses about the complex phenomena involved in translating. It is obvious that these observations have managed to create more questions than provide final answers. In fact, a lot more work needs to be done before we can even contemplate answering the questions inspired by protocol studies. The more we learn about the mechanisms underlying translation, the more we come face to face with unexplored areas. Pamela Gerloff's observation that translation does not get easier applies only too well to doing research on translation processes: it certainly does not seem to get any easier.

Notes

1. I am grateful to Tiina Puurtinen and Sonja Tirkkonen-Condit for their comments on an earlier version of this manuscript.

2. Small samples are admittedly a problem in experimental translation studies as well as in other kinds of empirical work, be it process- or product-oriented. However, the problem is not unique to translation studies where, one might add, experimentation is still a novelty. In psychology, with its vastly longer history in experimentation, the same problem still exists, which might help to alleviate the guilt of translation experimenters. For example, Guy Claxton (1980: 7-8) criticises the quality and quantity of subjects used in cognitive psychological experiments. In many psychological experiments it is not specified who the subjects are; yet the results are generalised to apply to all people. (In fact, many psychological theories are based on the behaviour of undergraduate psychology students or mental patients or, in the behaviourist era, laboratory rats.) In relation to the size of samples, Claxton (1980: 8) points out rather acidly: "Incidentally, the number of subjects used is typically rather small. Eight to twelve is common, though in one of the three experiments that Collins and Quillian [1969] report only three subjects produced usable data. I know that the statistics are supposed to take this into account, but still three Americans (of unspecified age and experience) seems rather inadequate as a sample from which to draw conclusions about humanity."

3. The source text dealt with medical research, and one of the free lance translators had worked for a medical company. As a result the topic of the target text represented a previous routine area for her. However, as the source text was a popularised medical text, and the intended target text even more so, the task can be regarded as a non-routine task. This mixture of a non-routine task and a routine area did in fact confuse this translator in some rather unfortunate ways (see Jääskeläinen, in print).

\section{REFERENCES}

ARNTZ, R. (Ed.) (1988): Textlinguistik und Fachsprache. Akten des Internationalen übersetzungswissenschaftlichen AlLA-Symposions, Hildesheim, 13.-16. April 1987, Hildesheim, Olms. 
ATKINSON, J. W. (1974): "Strength of Motivation and Efficiency of Performance", Atkinson and Raynor (Eds), Motivation and Achievement, New York, Wiley, pp. 193-218.

ATKINSON, J. W. and J. O. RAYNOR (Eds) (1974): Motivation and Achievement, New York, Wiley.

BÖRSCH, S. (1986): "Introspective Methods in Research on Interlingual and Intercultural Communication", House and Blum-Kulka (Eds), Interlingual and Intercultural Communication. Discourse and Cognition in Translation and Second Language Acquisition Studies, Tübingen, Narr, pp. 195-209.

CHESTERMAN, A. (in press a): "The Centipede Problem in Translation Teaching", Neubert et al. (Eds), Hauptergebnisse der V. Internationalen Konferenz zu Grundfragen der Übersetzungswissenschaft 'Alternative Modelle des Übersetzens', Kent $(\mathrm{OH})$, Kent University Press.

CHESTERMAN, A. (in press b): "From 'Is' to 'Ought': Translation Laws, Norms, and Strategies", TARGET.

CLAXTON, G. (1980): "Cognitive Psychology: A Suitable Case for What Kind of Treatment", Claxton (Ed.), Cognitive Psychology: New Directions, London, Routledge and Kegan Paul, pp. 1-25.

CLAXTON, G. (Ed.) (1980): Cognitive Psychology: New Directions, London, Routledge and Kegan Paul.

COLLINS, A. and M. QUILLIAN (1969): "Retrieval Time from Semantic Memory", Journal of Verbal Learning and Verbal Behavior, 8, pp. 240-248.

ERICSSON, K. A. and H. A. SIMON (1984): Protocol Analysis: Verbal Reports as Data, Cambridge (Mass), MIT Press.

FAERCH, C. and G. KASPER (Eds) (1987): Introspection in Second Language Research. Clevedon, Multilingual Matters.

GERLOFF, P. (1988): From French to English: A Look at the Translation Process in Students, Bilinguals, and Professional Translators, unpublished doctoral dissertation, Harvard University, University Microfilms International.

HÖLSCHER, A. and D. MÖHLE (1987): "Cognitive Plans in Translation", Faerch and Kasper (Eds), Introspection in Second Language Research, Clevedon, Multilingual Matters, pp. 113-134.

HÖNIG, H. G. (1988): "Übersetzen lernt man nicht durch Übersetzen. Ein Plädoyer für eine Propädeutik des Übersetzens", Fremdsprachen lehren und lernen, 17, pp. 154-167.

HÖNIG, H. G. (1992): "Von der erzwungenen Selbstentfremdung des Übersetzers — Ein offener Brief an Justa Holz-Mänttäri", TextConText, 7, pp. 1-14.

HOUSE, J. (1988): "Talking to Oneself or Thinking with Others? On Using Different Thinking Aloud Methods in Translation", Fremdsprachen lehren und lernen, 17, pp. 84-98.

HOUSE, J. and S. BLUM-KULKA (Eds) (1986): Interlingual and Intercultural Communication. Discourse and Cognition in Translation and Second Language Acquisition Studies, Tübingen, Narr.

HOWARD, D. V. (1983): Cognitive Psychology. Memory, Language, and Thought, New York, MacMillan.

IZARD, C. E., KAGAN, J. and R. B. ZAJONC (Eds) (1984): Emotion, Cognition, and Behavior, New York, Cambridge University Press.

JÄÄSKELÄINEN, R. (1987): What Happens in a Translation Process: A Think-aloud Protocol Study, unpublished pro gradu thesis, University of Joensuu, Savonlinna School of Translation Studies.

JÄÄSKELÄINEN, R. (1989a): "The Role of Reference Material in Professional vs. Non-professional Translation: A Think-aloud Protocol Study", Tirkkonen-Condit and Condit (Eds), Empirical Studies in Translation and Linguistics, Joensuu, University of Joensuu, Faculty of Arts, pp. 175-200.

JÄÄSKELÄINEN, R. (1989b): "Translation Assignment in Professional vs. Non-professional Translation: A Think-aloud Protocol Study", Séguinot (Ed.), The Translation Process, Toronto, H. G. Publications, pp. 87-98.

JÄÄSKELÄINEN, R. (1990): Features of Successful Translation Processes: A Think-aloud Protocol Study, unpublished licentiate thesis, University of Joensuu, Savonlinna School of Translation Studies.

JÄÄSKELÄINEN, R. (1993): "Investigating Translation Strategies", Tirkkonen-Condit and Laffling (Eds), Recent Trends in Empirical Translation Research, Joensuu, University of Joensuu, Faculty of Arts, pp. $99-120$.

JÄÄSKELÄINEN, R. (in press): "The 'Human Translator' in the Light of Verbal Report Data", Neubert et al. (Eds), Hauptergebnisse der V. Internationalen Konferenz zu Grundfragen der Übersetzungswissenschaft 'Alternative Modelle des Übersetzens', Kent (OH), Kent University Press.

JÄÄSKELÄINEN, R. and S. TIRKKONEN-CONDIT. (1991): "Automatised Processes in Professional vs. Nonprofessional Translation: A Think-aloud Protocol Study", Tirkkonen-Condit (Ed.), Empirical Research in Translation and Intercultural Studies. Selected Papers of the TRANSIF Seminar, Savonlinna 1988, Tübingen, Narr, pp. 89-110.

KÖNIGS, F. G. (1987): "Was beim Übersetzen passiert. Theoretische Aspekte, empirische Befunde und praktische Konsequenzen", Die Neueren Sprachen, 86-2, pp. 162-185.

KRINGS, H. P. (1986): Was in den Köpfen von Übersetzern vorgeht. Eine empirische Untersuchung zur Struktur des Übersetzungsprozesses an fortgeschrittenen Französischlernern, Tübingen, Narr. 
KRINGS, H. P. (1988): "Blick in die 'Black Box' - Eine Fallstudie zum Übersetzungsprozeß bei Berufsübersetzern", Arntz (Ed.), Textlinguistik und Fachsprache. Akten des Internationalen übersetzungswissenschaftlichen AlLA-Symposions, Hildesheim, 13.-16. April 1987, Hildesheim, Olms, pp. 393-412.

KUBMAUL, P. (1991): "Creativity in the Transiation Process: Empirical Approaches", van Leuven-Zwart and Naaijkens (Eds), Translation Studies: The State of the Art. Proceedings from the First James $S$. Holmes Symposium on Translation Studies, Amsterdam, Rodopi, pp. 91-101.

LAUKKANEN, J. (1993). Routine vs. Non-routine Processes in Translation: A Think-aloud Protocol Study, unpublished pro gradu thesis, University of Joensuu, Savonlinna School of Translation Studies.

LEWANDOWSKA-TOMASZCZYK, B. and M. THELEN, (Eds) (1992): Translation and Meaning, Part 2, Rijkshogeschool Maastricht, Faculty of Translation and Interpreting.

LÖRSCHER, W. (1991): Translation Performance. Translation Process, and Translation Strategies. A Psycholinguistic Imvestigation, Tübingen, Narr.

NAGY, U. (1989): Zum Übersetzungsprozeß: Eine Protokolluntersuchung der Unterschiede beim Hin- und Herubersetzen von fortgeschrittenen Deutschstudenten, unpublished pro gradu thesis, University of Joensuu, Savonlinna School of Translation Studies.

NEUBERT, A. et al. (Eds) (in press): Hauptergebnisse der V. Internationalen Konferenz zu Grundfragen der Übersetzungswissenschaft 'Alternative Modelle des Übersetzens', Kent $(\mathrm{OH})$, Kent University Press.

PÖNTINEN, T. A. and T. M. ROMANOV (1989): Professional vs. Non-professional Translator: A Think-aloud Protocol Study, unpublished pro gradu thesis, University of Joensuu, Savonlinna School of Translation Studies.

SÉGUINOT, C. (1989a): "The Translation Process: An Experimental Study", Séguinot (Ed.), The Translation Process, Toronto, H.G. Publications, pp. 21-54.

SÉGUINOT, C. (Ed.) (1989b): The Translation Process, Toronto, H.G. Publications.

SIMON, H. A. (1956): "Rational Choice and the Structure of the Environment", Psychological Review, 63, pp. $129-138$.

SIMON, H. A. (1979): Models of Thought, New Haven, Yale University Press.

TIRKKONEN-CONDIT, S. (1989): "Professional vs. Non-professional Translation: A Think-aloud Protocol Study", Séguinot (Ed.), The Translation Process, Toronto, H.G. Publications, pp. 73-86.

TIRKKONEN-CONDIT, S. (1992): "The Interaction of World Knowledge and Linguistic Knowledge in the Processes of Translation. A Think-aloud Protocol Study", Lewandowska-Tomaszczyk and Thelen (Eds), Translation and Meaning, Part 2, Rijkshogeschool Maastricht, Faculty of Translation and Interpreting, pp. $433-440$.

TIRKKONEN-CONDIT, S. (Ed.) (1991): Empirical Research in Translation and Intercultural Studies. Selected Papers of the TRANSIF Seminar, Savonlinna 1988, Tübingen, Narr.

TIRKKONEN-CONDIT, S. and S. CONDIT (Eds) (1989): Empirical Studies in Translation and Linguistics, Joensuu, University of Joensuu, Faculty of Arts.

TIRKKONEN-CONDIT, S. and J. LAFFLING. (Eds) (1993): Recent Trends in Empirical Translation Research, Joensuu, University of Joensuu, Faculty of Arts.

TOURY, G. (1984): “The Notion of 'Native Translator' and Translation Teaching", Wilss and Thome (Eds), Die Theorie des Übersetzens und ihr Aufschlußwert für die Übersetzer- und Dolmetscherausbildung, Tübingen, Narr, pp. 186-195.

TOURY, G. (1991): "What are Descriptive Studies into Translation Likely to Yield apart from Isolated Descriptions?", van Leuwen-Zwart and Naaijkens (Eds), Translation Studies: The State of the Art. Proceedings from the First James S. Holmes Symposium on Translation Studies, Amsterdam, Rodopi, pp. 179-192.

VAN LEUVEN-ZWART, K. M. and T. NAAIJKENS (Eds) (1991): Translation Studies: The State of the Art. Proceedings from the First James S. Holmes Symposium on Translation Studies, Amsterdam, Rodopi.

WILSS, W. and G. THOME (Eds) (1984): Die Theorie des Übersetzens und ihr Aufschlußwert für die Übersetzer- und Dolmetscherausbildung, Tübingen, Narr. 